\title{
Nitrate distribution pattern under conventional and trickle irrigation system
}

\author{
Arpna Bajpai* and Arun Kaushal ${ }^{1}$ \\ Department of Soil and Water Engineering, Jawaharlal Nehru Krishi Vishwa Vidyalaya, Jabalpur (M.P.) India \\ (Email: arpnabajpai@gmail.com)
}

\begin{abstract}
Nitrate is a highly mobile ions that moves with water. So that nitrate distribution around the driplines is strongly affected by irrigation and fertigation strategy. Nitrate movement under conventional flood irrigation system was observed 2 to 3.5 times faster as compared with trickle irrigation as well as $\mathrm{NO}_{3}{ }^{\prime \prime}-\mathrm{N}$ concentrations exceeded the threshold limit $\left(i . e .10 \mathrm{mg} \mathrm{l}^{1^{-1}}\right)$ under traditional irrigation method, while stayed below the threshold limit under micro irrigation methods. Nitrate distribution was influenced by hydraulic properties, drip discharge rate, soil layering, timing of nutrient application and irrigation frequency. To maintain larger amounts of nutrient nearby emitter in highly permeable coarse-textured soils, nutrients must be applied at the starting of an irrigation cycle so that it is less susceptible to leaching losses. Study revealed that higher transpiration raised the $\mathrm{NO}_{3}-\mathrm{N}$ uptake by the plats. The study also revealed that urea moves promptly with irrigation water and urea-ammonium-nitrate fertilizer increased the nitrate concentration, near the drip line immediately after the drip fertigation due to the nitrification, while low concentrations was found near the periphery of the wetting zone.
\end{abstract}

Key Words : Conventional irrigation system, Drip line, Fertigation, Trickle irrigation, Nitrate Distribution Pattern

View Point Article : Bajpai, Arpna and Kaushal, Arun (2021). Nitrate distribution pattern under conventional and trickle irrigation system. Internat. J. agric. Sci., 17 (2) : 740-744, DOI:10.15740/HAS/IJAS/17.2/740-744. Copyright@2021: Hind Agri-Horticultural Society.

Article History : Received : 04.03.2021; Accepted : 20.03.2021

\footnotetext{
*Author for correspondence:

${ }^{1}$ Department of Soil and Water Engineering, Punjab Agricultural University, Ludhiana (Punjab) India (Email: arunkaushalarun@rediffmail.com)
} 